\title{
The Welfare Effects of Trade in Phytomedicines: A Multi-Disciplinary Analysis of Turmeric Production
}

\author{
AnthonyBooker (anthony.booker.11@ucl.ac.uk) 1,2 Deborah Johnston (dj3@soas.ac.uk) 1,3, \\ Michael Heinrich (m.heinrich@ucl.ac.uk) 1,2
}

1) Leverhulme Centre for Integrative Research on Agriculture and Health, (LCIRAH) 36 Gordon Square, London, WC1H OPD, UK.

2) UCL School of Pharmacy, 29 - 39 Brunswick Square, London, WC1N 1AX, UK

3) SOAS University of London, Thornhaugh Street, Russell Square, London, WC1H OXG, UK

This research was funded by the Leverhulme Trust through a grant to LCIRAH

Corresponding author: Deborah Johnston, dj3@soas.ac.uk. Office - +44-207-898-4494

(note: no fax service). Mobile - +44-7950-494718

\section{ABSTRACT}

International trade in medicinal herbal products is growing, while value chains are becoming more complex and governed by a range of public and private standards. There is a debate over the extent to which phytomedicine production can be beneficial for farmers in low and middle income countries. More generally, there are varied views about the extent to which small farmers are disadvantaged by stringent public health and private consumer standards in northern markets for agricultural products. This paper proves a comparative analysis of value chains, using case studies of turmeric production in India. It marries a qualitative investigation of turmeric producing sites in India with an investigation into the chemical quality of various turmeric products. The aim of the paper is to understand the way that varied structure and governance of value chains changes the benefits to both producer and consumer. When production is for the organic northern market, we found evidence of a 'captive' value chain, where the lead firm requires strict adherence to conditions of production and processing. Prices for farmers were relatively stable, at a reasonably high level. In contrast, where farmers were producing for local markets, including the major auction at Erode, prices were volatile and farmers bore considerable risk. We found that competition and volatility in the market-based chain can lead to turmeric adulteration and contamination, both intentional and unintentional. Our case study suggests that many small turmeric farmers would find it difficult to meet both public and private health standards, in contrast to some academic literature that argues that public health standards do not discriminate against small farmers. More than this, our study adds to the discussion of the impact of standards, suggesting clear consumer benefits in northern markets. However, there are also indications that only larger and more dynamic farmers can participate in the lucrative phytomedicine trade. As such, our study tentatively supports previous literature suggesting that the application of standards in northern markets lead to increasing farmer differentiation.

KEY WORDS: phytomedicines, value chains, standards, turmeric, India, herbal products 
Introduction

While there is a long history of trade in phytomedicine, (defined as medicinal products prepared from plants and used in the form of extracts or ground plant material), growth in the last few decades has been particularly rapid (Robinson \& Zhang 2012:5-6). Inconsistent terminology confounds clarity on production estimates, but the value of traditional medicine production (including herbal, mineral and animal products) was estimated to be worth US\$83 Billion in 2008 (Robinson and Zhang, 2012), on par with the American weight loss industry (\$ 61 Billion) (LaRosa, 2011) or the worldwide cosmetics industry (\$170 Billion) (Romanowski, 2010). Further, medicinal plant trade may be even more volatile than standard agricultural trade, as it is susceptible not only to weather shocks and disease outbreaks, but also to rapid changes in consumer fashions. Heinrich et al (2011) note that the declaration of an herbal medicinal product as a superfood leads to sudden consumer booms and rapid price rises.' A prime example is Honeysuckle, which is used in Influenza treatments and has recently been added to health drinks in China; consequently the price has increased from a stable average of US\$20 per kilo over the period 2004 to 2008 to almost US\$100 per kilo in 2010 (Yeoh, 2010). This price volatility is likely to be greater at the level of the individual country, as global market volatility is compounded by sudden changes in the sourcing practices of dominant buyers, who provide access to lucrative Northern markets (Neimark 2012:431-2).

This article will use the example of turmeric from India to explain how, along with changes in trade and production volumes, the nature of the value chains that link producer with consumer have grown more complex. Using an innovative multi-disciplinary approach, this paper is able to comments not only on market outcomes and participation, but also on product quality by including a study of chemical composition. 
Overall the paper argues that in the case study areas, farmers who can sell medicinal turmeric to quality-controlled export markets are able to achieve more stable prices than those that sell it for food use in local markets. This in itself is unsurprising. What is of interest is the way that both public and private standards change market outcomes and participation. We shall see that there has been a debate about the impact of standards, commonly separated into public and private standards. Standards, like state-encoded health standards, may be thought of as public, as states regulate and enforce these standards. An example of the relevant public health standards in this case, are those produced and encoded by The Food Standards Agency (FSA) who are responsible for the safety and quality of foods and food supplements in the UK. Private standards are those that are adopted voluntarily by companies or organizations, even though they may be codified at the international level. In this case study, organic production is defined as a private standard.

We find that standard setting forces lead firms into closer relationships with producers. For consumers of turmeric, this leads to a superior product if assessed in terms of pesticide, colorant and preservative addition, as well as active chemical compounds. There are clearly benefits for farmers who can participate in these higher value chains. However, these are likely to be large or middle-sized dynamic farmers. As such the paper is important in extending our understanding of the impact of public and private standards on the benefits of trade (Melo et al 2014).

The overall implication of our research is that the constrained access to high value Northern markets and the complex public and private regulation of medicinal turmeric means that only richer farmers can participate. However, the quality of the product is far higher than that in unregulated markets, where market competition and volatility lead to adulteration. This paper contributes to the small literature on global value chains (GVCs) in phytomedicine. In its discussion of a 'captive' value chain, using the definitions set out in Gereffi et al (2005), our research also confirms many of the concerns raised in wider literature on food safety regulations and quality standards. Importantly, it adds to the debate over the impact of 
standards by combining qualitative analysis with the chemical analysis of turmeric products. Linking the results allows us to consider some aspects of the impact of standards commonly excluded in the literature - that is the impact for consumers.

In methodological terms, the choice of contrastive case studies, semi-structured interviewing and non-participant observation has its strengths in uncovering the dynamics behind participation in particular value chains. However, it does preclude making strong statements about the net impact of various kinds of value chain on producers. At the same time, given the complexity of the issues raised by the trade in phytomedicines, this paper illustrates how inter-disciplinary approaches can give new insights.

The paper first reviews the literature on the impact of standards in agricultural value chains, before setting out the nature of phytomedicine production in India. The case study and research methods will then be outlined. The first of two results sections will describe the various value chains for turmeric, while the second will set out the character of standards and governance in those chains. The article ends with a discussion of the implications of this research for the wider debate over the value of agricultural standards and the impact of phytomedicine trade.

Trade and standards in agri-food value chain framework

Barrett et al (2012) argue that the emergence of export value chains benefits participant farmers, who will improve their productivity and profitability, and in doing so, contribute to economic development. However, they recognize that the size of the benefit to participating farmers is uncertain, and is likely to be smaller where there are unanticipated risks or where buyers enjoy contractual bargaining power over farmers. There has been a long debate over the impact of contract farming (see Bellemare 2012, Masakure \& Henson 2005). Bellemare's (2012) study of the impact of contract farming in Madagascar suggested a small 
positive income benefit, using an innovative statistical methodology that attempted to control for the differences between contract farming participants and non-participants. However, much of the debate has moved away from looking at average impacts to looking at the distributional impacts, with Watts arguing that contract farming promotes social differentiation (1994:54).

The GVC approach, with its investigation of power relations in agri-food chains (Fullbright, 2008; Gibbon and Ponte, 2005; Kaplinsky, 2004), can illuminate some of the reasons for differential outcomes, but has only been applied in a limited way to medicinal plant products. Where research has taken place, there is a concern that significant power imbalances in the chain work against producers and Neimark (2012:424) has referred to these imbalances as 'green grabbing', arguing that the collectors of plants are at extreme disadvantage to pharmaceutical companies.

The strengths and weaknesses of the GVC approach have been debated widely, with concern that it cannot effectively analyze consumption and employment (Smith et al., 2002; Bernstein and Campling, 2006; Bair, 2005; Palpacuer, 2008; Riisgaard 2009). The GVC analysis usually ends at the level of the retailer (rather than consumer) and begins with the farmer (rather than the farmworker) (Bair, 2005). Similarly, our paper does not investigate how the demand for turmeric is formed in Northern markets, neither does it consider the environmental, gender or labor issues related to turmeric production. As such, the study raises issues for future investigation."

Using the GVC approach, many authors suggest that lead firms have increasing power in agricultural value chains due both to greater market concentration and more stringent food safety regulations in northern retail markets (e.g. Selwyn, 2007; Ortiz and Aparicio 2007). Thus, the application of public and private regulations is a key issue in shaping power relations in agricultural value chains. Among the positive effects of regulations, they generate a common language for all in the value chain and stimulate demand by increasing 
consumer confidence (Melo et al 2014). On the negative side, certain farmers suffer due to an inability to meet standards. Crucially Melo et al (2014) argue that the impacts are complex and extrapolating from one example of standards imposition can result in misleading estimates of their impact. However, Coslovsky (2014:33) summarizes the empirical evidence to suggest that small producers, those in the poorest countries, and those exporting lightly processed commodities tend to experience the largest losses when standards are introduced.

In their review of the literature, Hansen and Trifkovic (2014) argue that the impact of food standards may induce negative externality effects on poor farmers because the inability to comply with food safety and quality standards in high value markets can result in selling to far less profitable alternatives. Similarly, they argue that it could be the case that the richest farmers already received high prices (for their high quality output) and so find that there is no gain from adopting new standards. In their study of the impact of standards on the pangasius value chain in Vietnam, the overall outcome of food standards seems to be positive only for upper-middle class farmers, while others only benefit from better labor market opportunities. However, not all standards are likely to have the same impact (Melo et al 2014). Tran et al's (2013) study of the shrimp sector suggests that food safety standards are within reach for small-scale shrimp producers, as generally they do not use antibiotics or other prohibited chemicals. However, the traceability requirements of social and environmental standards lead some processors to consider producing shrimp themselves or to promote vertical integration with larger shrimp producers. Both approaches facilitate traceability, but marginalize small-scale shrimp farmers and traders, forcing them to produce only for less profitable and more volatile domestic and regional markets. Thus, Tran et al (2013) conclude that it is private, rather than public, standards that disadvantage small farmers. 
Of the 17,000 plants to be found in India, 7,500 are known for medicinal uses (Kala et al., 2006), with Ayurvedic medicine iii $^{\mathrm{i}}$ claiming to use 2,000 of these. More than 60 species are in great demand (Patwardhan et al., 2005), with the annual turnover of the Indian herbal medicine industry estimated between US\$377 million and US\$1 billion per annum (Kala et al., 2006; Sharma et al., 2008). A recent study commissioned by India's National Medicinal Plants Board (NMPB) has estimated that 177,000 metric tons of medicinal plants are used each year by India's domestic herbal industry, that 86,000 metric tons are employed within rural Indian households, and that 56,500 metric tons are exported through international trade (Cavaliere, 2010). While Indian exports, valued at US\$132 million in 2008, contributed less than $0.2 \%$ to the global herbal market, growth is rapid and Indian companies are fast emerging as key international suppliers of medicinal plants.

The structure of the industry is diverse. Herbal medicinal products are produced by several thousand companies in India, most of whom are quite small, including numerous neighborhood pharmacies that compound ingredients to make their own remedies (Dharmananda, 2003). The exact number of manufacturers is unclear, with estimates ranging between 1,200 and 6,000 licensed manufacturers (Subrat et al., 2002),(Polshettiwar, 2006). However, it is generally agreed that the formal sector of the industry is dominated by around a dozen major companies, most of whom produce products other than phytomedicines, such as foods and toiletries (Dharmananda, 2003). In 2012, Emami was the leading company, with a market value share of $17 \%$, followed by Darbur $(16 \%)$ and Proctor and Gamble (11\%), reflecting a more general rise in market presence from non-Indian companies (Euromonitor, 2013). These manufacturers are supplied by local or national markets, directly from farms or commonly through middlemen representing wild pickers. The vast majority of medicinal plant species used in India to make herbal medicinal products (HMPs) are still collected from the wild although there is evidence to suggest that some companies are developing more sustainable cultivation strategies (Cavaliere, 2010), 
The globalization of Ayurvedic practices has gained momentum over the last twenty years and Ayurvedic products are used as food supplements in the USA, Europe and Japan. (Ravishankar and Shukla, 2007). Certainly, exports of herbal products from India increased to US\$128 Million in 2009-10, from US\$69 Million in 2005-06, recording a compounded annual growth rate of 16.8 per cent. Between 2007 and 2010, the top five export destinations were USA, Pakistan, Germany, Japan, and the UK (Scindia, 2010). However, the UK share declined in relative and absolute terms over this period (from $\$ 3.7$ million in 2007-08 to $\$ 3.2$ Million in 2009-10). This may be as a result of the implementation of the THMPD which, it has been argued, raises the entry bar for producers of these types of plant based medicines to enter the European market (Patwardhan, 2011). Professional practitioners of Traditional Indian Medicine (TIM), including Ayurveda, are scarce in the UK compared with Western herbalists or Traditional Chinese Medicine (TCM) practitioners and medicinal herbal products are generally sought out by the general public in retail health food shops or using online websites (Booker, 2014).

Indeed, it has been argued that despite healthy growth in Indian medicinal plant exports, adulteration and contamination are commonplace and so the supply of good quality raw materials is limited (Patwardhan et al., 2005). With an estimated 95\% of herbal species wildcollected, the resulting depletion of wild medicinal plants affects not only bio-diversity and the ecology but can also have a serious detrimental impact on the livelihoods of local people (Kala et al., 2006). Many argue that the cultivation of wild herbal plants should be the aim of policy, along with tighter regulations on herbal-collection (Alam and Belt, 2009; Kala et al., 2006; Schippmann et al., 2002).

There is some agreement that the sustainable cultivation of medicinal plants would require a combination of support to production (to raise yields) and to processing (to improve quality) as well as intervention in the value chain. The unregulated marketing system for phytomedicinal products means that farmers are often unaware of final market prices and lack knowledge of the marketing system. Without intervention in both production and value 
chains, small farmers will continue to benefit little and that many medicinal plants are destined to be traded through illegal channels Kala et al., (2006), van de Kop et al., (2006) come to similar conclusions, pointing out that high risks, transaction costs and a lack of trust amongst chain actors prevent small-holder producers from taking up the cultivation of medicinal plants. Assessing a project to cultivate a medicinal plant, Kutki (Picrorhiza kurroa Royle ex Benth.) in northern India, Alam and Belt (2009) find that the project had disappointing results due to poor quality of planting material, lack of irrigation, and the emergence of apples as a profitable cash crop, resulting in farmers switching away from kutki. Alam \& Belt (2009) conclude that the cultivation of medicinal plants is more difficult than usually portrayed in the scientific literature and government promotional material.

Public-private collaborations are suggested as a way of minimizing constraints to cultivation, with support from agricultural extension and research agencies (Kala et al., 2006; Vaidya and Devasagayam, 2007; van de Kop et al., 2006). In contrast, Shahidullah \& Haque (2010) argue that there needs to be stronger vertical integration in the value chain, in order to remove barriers to market access on the part of producers, improve producers' power in the chain and give manufacturers greater control over quality and supply.

Case study and research methods

The case study phytomedicine studied here was Curcuma longa L., or turmeric. Turmeric is an important phytomedicine crop, used in Ayurvedic and alternative medicine generally, as well as being used for food. In 2007, Indian turmeric had a total export value of US\$ 14 million. This rose to an estimated all time high of nearly US\$120 million in 2012 (Spices Board, 2015). In the most common form of production in India, turmeric roots are dried in the sun, boiled to soften, re-dried and then subjected to a polishing process to improve the texture and color of the root thereby making it potentially more attractive to the buyer. ${ }^{\text {iv }}$ 
As well as food use, turmeric has various spiritual and medicinal uses in India. It is associated with the cleansing of the body and is commonly used by women on the last day of menstruation or upon marriage (Velayudhan et al., 2012). It is indicated as an antiinflammatory and for the treatment of flatulence, jaundice, menstrual difficulties, hematuria, hemorrhage, and colic, and as an external treatment, it is used in poultices to relieve pain and inflammation (Thorne, 2002). In western medicine, current research has focused on turmeric's antioxidant, hepato-protective, anti-inflammatory, anti-carcinogenic, and antimicrobial properties, in addition to its use in cardiovascular disease and gastrointestinal disorders (Thorne, 2002). Various tests have been carried out, often citing turmeric's curcumin content (or a mixture of curcuminoids) as the main active ingredient (Booker et al., 2014). The clinical effectiveness of curcumin is hampered by its poor bio-availability and large prescribed doses, e.g. $8 \mathrm{~g} /$ daily may be required to achieve any therapeutic benefit (Jurenka, 2009). This has led to the development of high potency curcumin extracts and various chemically modified spin off products purported to be more easily absorbed (Booker, 2014).

Turmeric's use as both food and a medicine presents an opportunity to show how complex value chains may be for certain herbal products. One major difference between the various uses (food, ritual and medicine) is the nature of standards, and this helps us understand better the influence of public and private standards. The literature on standard setting and contract farming highlights the difficulty of investigating impact, not least because of the difficulty of comparing participants with non-participants who may not be similar (Barrett et al 2012, Bellemare 2012). Bellemare (2012) notes that, despite the potential for some sophisticated matching techniques, it was still difficult to completely control for the differences between participants and non-participants, and also that it was unclear if results were externally replicable, as contract farming tended to take place in very particular areas (such as close to roads and airports). 
It was important to identify sites that had experience in cultivation and trade. Karnataka and Tamil Nadu are major turmeric growing areas. This research uses a comparative analysis of commodity chains, using three case study sites that reflect two different types of turmeric value chain. There are two types of value chain relationship illustrated here - using the definitions set out in Gereffi (2005), the research provides examples of both market-based and captive value chains. The former are value chains were linkages are market-based and switching cost are low, while the latter are chains were small suppliers are dependent on much larger buyers and so are described as 'captive' as they face significant switching costs. At the same time, in 'captive' value chains, there is a high degree of monitoring by lead firms to ensure product quality and also attempts to control the sales behavior of small suppliers so that they do not sell to others. Other authors have used the term 'vertically integrated' to reflect the relative difference in power in this value chain between suppliers and the lead firm (e.g. Shahidullah \& Haque 2010).

The first case study examined a farm site located near to Shimoga in the state of Karnataka. This was an example of a farm that was in a captive chain, supplying at a national level a primary manufacturing site in Bangalore and internationally to a secondary manufacturing site in the UK. 
Market-based chain (Case Study 2, Erode)

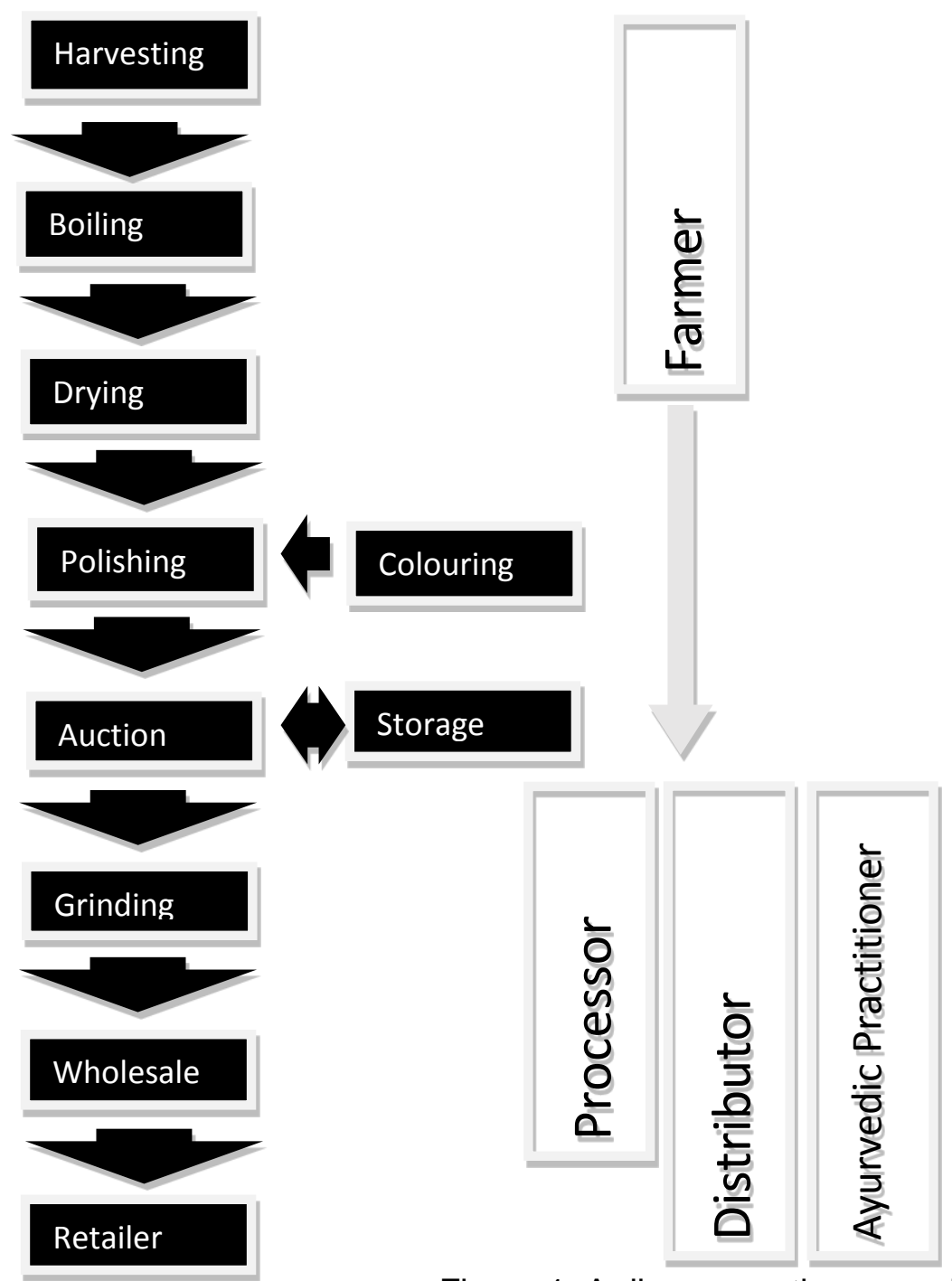

Captive Chain (Case Study 1, Shimoga)

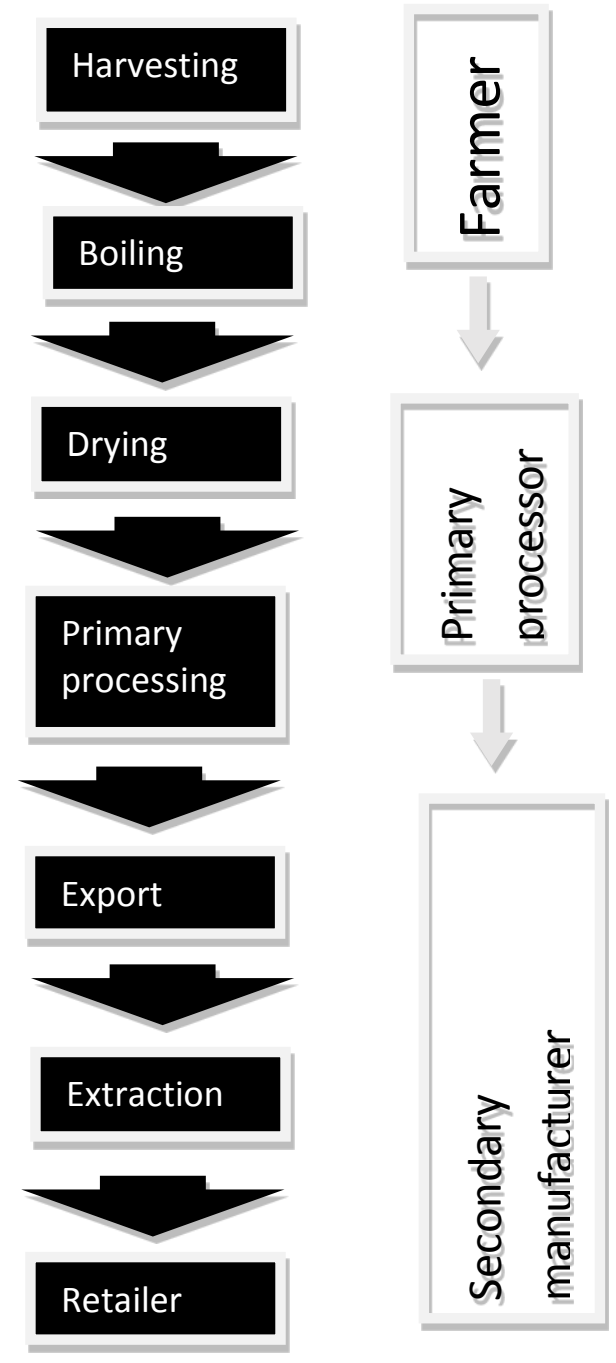

Figure 1: A diagrammatic comparison of the Erode and Shimoga value chains 
There are two examples of market-based chains in this research, reflecting the different end usages of turmeric. The second case study is of a market-based value chain, and this examined a farm site near to Erode in the state of Tamil Nadu. In India, Tamil Nadu is a major area for the cultivation of Curcuma longa and the town of Erode, also known as 'turmeric city', is regarded as the world's largest producer and the most important trading center in India (Prasad and Aggarwal, 2011). This site grew plant material that would be sold through middlemen at an auction house and represented the traditional route of supply where the plant material could be bought by any buyer for a multitude of purposes (e.g. food and medicinal use), including being purchased by a local manufacturing unit and once traded the traceability of the material was generally lost. The third site was in Jhansi, northern India that sold turmeric only to local market traders and had no connection with, and little understanding of, the industrial chain. While there would be less confounding information if all three of the sites were in the same state, these sites provided a good comparison between a captive and market chain.

Qualitative data was collected for each of the diverse value chains, using semi-structured interviews and non-participant observation at several points in the chain. Semi-structured interviews are useful in obtaining a range of insights on a specific issue. This methodology had advantages over a fully structured approach in that it was less intrusive, encouraging two way communication. It was able to both confirm what was already known and provided an avenue for learning with the interview subjects being able to provide the reasons behind their answers as described by (FAO, 1990). Observational methods (Handley, 2012) offered an insight into what people do rather than what they say they do. Moreover, an observational and interview approach is in line with what would be regarded as 'best practice' in research connected with GVC analysis (Kaplinsky and Morris, 2001). This recommends that actors at various stages of the value chain are interviewed in order to establish value chain dynamics. 
Chemical analysis of 54 turmeric samples (12 extracts, 32 ground powders, 7 dried roots/rhizomes, 3 fresh rhizomes) was carried out using a combination of $\mathrm{H}$ - nuclear magnetic resonance (NMR) spectroscopy coupled with multivariate analysis and high performance thin layer chromatography (HPTLC) (Booker et al., 2014). Both techniques provide different and complementary data and together they can be used to effectively differentiate between a wide variety of crude drug powders and herbal medicinal products, offering new ways to understand how chemical quality may potentially be linked to the governance and arrangement of a value chain. Samples were collected from various sources: fresh turmeric from the local markets at case study sites 2 and 3 ; the product of the captive value chain, case study 1; and other medicinal turmeric products on sale in the UK, which were in powders, extracts or in tinctures. Each sample was tested for curcuminoid content and its general chemical profile, and compared to the pure samples of the fresh product (as recorded in pharmacognosy literature). A full description of the analytical methods and results is provided by Booker et al. (2014).

For the qualitative study, the core sample (see Table 1) was comprised of farmers, processors and market traders (interviewees were located when primary respondents recommended subsequent interviewees, i.e. through 'snowballing'). It proved problematic to interview farmworkers due to the lack of ability to communicate in regional languages. Some impression was gained of pay and working conditions through observation and other interviews, although this is likely to have been highly imperfect. In addition to the specific interviewees listed in Table 1, visits were made to markets, trade fairs and Ayurvedic hospitals, and interviews carried out with manufacturers, regulators, local academics, NGO's active in the area, exporters, and retailers. Notes were made from the local newspapers of any news stories relating to export trade, agriculture and herbal medicines.

Research was carried out during times of high activity in 2012. The busy period for turmeric production runs from November through to April, when most harvesting, drying, processing 
and trading takes place. Research was carried out for four months, split over two visits, one in January and February 2012 (Shimoga and Erode) and the second in October and November 2012 (revisiting the primary sites, and then travelling to Jhansi). The primary author spent time interacting with the participants in order to gain their trust and attempt to break down some of the barriers. Despite giving clear information about the nature of the project, the primary author did suspect that respondents in some cases believed that the research was linked to particular herbal manufacturers or to a local university that had provided introductions. As such, it is unlikely that he heard the most negative aspects of employment on the farm or in a factory or heard grievances regarding poor pay and / or working conditions. Permissions were given for interviews, and ethical approval for the fieldwork given by the London School of Pharmacy on 25/11/2011 (Research Ethics Committee References REC/B/11/01).

\section{TABLE 1 ABOUT HERE}

The choice of contrastive case studies, semi-structured interviewing and non-participant observation is helpful in investigating the structure of particular value chains. However, it does preclude making strong statements about the net impact of various kinds of value chain on producers, as no clearly matched control group is established, while data on costs and revenue is obtained from a small sample. At the same time, given the complexity of the issues raised by the trade in phytomedicines, this paper does illustrate the operation of key features of various value chains, while the inter-disciplinary approach allows us to investigate quality for consumers by the use of chemical tests.

Structure of various value chains for turmeric in India

The structure of two value chains are sketched out here: one is the example of organic turmeric production for medicinal use (figure 1); the second is the domestic value chain for 
turmeric, where the product might be eventually used for local food, ritual or medicinal purposes. Case study 1 fits into the first value chain, which we have categorized as a 'captive' chain, while case studies 2 and 3 fit into the second type, which we have categorized as a market-based chain.

Case study 1 is set near to the city of Shimoga in the state of Karnataka. Here we find a supplier of organic, medicinal quality turmeric in the form of a 30 acre farm set in 450 acres of forest, managed by an environmental management trust. The farm is much larger than most farms in the area, and indeed in India in general, where the average size farm is approximately 3 acres and large farms (greater than 25 acres) account for only 1.0 percent of the total (USDA, 2009). The farm has been certified organic since 2004, and produces raw herbal ingredients (including turmeric) under contract to a Bangalore manufacturing company who then sells on to a European manufacturer. For turmeric, the farm received US\$1 per kilo - more than double the amount received in Erode in 2012, although far less than when turmeric prices were at a high in 2010. Areca is the principal crop grown on the farm and provides the forest canopy under which many of the medicinal plants are cultivated. Many of the medicinal plants are planted randomly under the areca canopy (wildcrafted) and there are no chemical pesticides or herbicides used and the crops in the fields are mostly weeded by hand. In addition, a range of other food crops are grown.

In Shimoga, the turmeric seed tubers are wild-crafted and after nine months the new root crop is ready for harvesting. Unlike the turmeric grown in Erode (case study 2 below), there is no polishing step (see fig. 1) and after drying, the rhizomes are sent to a company in Bangalore for processing. The company specializes in the supply of organic medicinal plants for the export market and have established contracts with farmers in Karnataka and throughout India to buy their organically-produced crops. In turn this company has a contract 
with a retailer in the UK who will buy the plants once they have been initially processed. This normally involves further cleaning, drying, cutting and powdering. The secondary processing -the transformation into a finished product ready for sale in store - takes place in the UK. The Bangalore based company began trading in 1999 and currently employs 150 people. According to the owner, the company did not start to make a profit until year eight and in the early years was heavily subsidized with funds from other businesses. It continues to grow by $20-30 \%$ each year. The company's product range includes: medicinal plant products, produced exclusively for the UK market; organic spices; organic compost; and a range of bio-pesticides. Along with the medicinal plant products, almost all of the spices are exported but recently the company has been experimenting with a spice range for the growing domestic market.

The Bangalore based company make direct contracts with the farmer and do not buy any material from market sources where traceability cannot be assured. All of the farms who supply the Bangalore operation are required to be certified by an international organic certification body. Both the farmer interviewed and the company respondents reported that farmers who contract with the company receives a $10-40 \%$ premium above the market price depending on the complexity of cultivation and the good agricultural practices that need to be used e.g. ginger $30-40 \%$, turmeric $10 \%$, coffee $10 \%$, pepper $20 \%$, white pepper $30 \%$. The premium is adjusted depending on the conventional market price. If the market price is low, the premium paid is higher, but if the market price is high, a lower premium is paid. This helps to achieve price stability.

This can be contrasted with the example of production for the domestic market, in the next two case studies. In case study 2, at the Erode site, one farm is owned by three reasonably wealthy brothers, each with ten acres of land. The farm produces turmeric and sells it at the major auction in Erode. In interviews, the brothers reported that they would like the 
opportunity to contract with European buyers but are less inclined to introduce organic farming which they consider as a more difficult process with greater risks of failure.

However, the price of turmeric in the Erode market is prone to fluctuation. According to interviews with farmers, in the 2009 / 2010 season, the price of turmeric soared to approximately US\$247 per quintal (100kg), but by April 2012 , the market price for Erode turmeric plummeted to below US\$60 per quintal (NCDEX 2015). The farmers interviewed in Erode blamed this price crash on over-production resulting from the high prices seen the previous years.

\section{FIG 2 ABOUT HERE}

This yo-yo effect results in a situation where farmers are forced to store the dried roots until the price rises to an acceptable level. However, storage facilities are still relatively basic and, while turmeric can be stored for up to five years, there is an appreciable risk of contamination from undesirable vectors such as insects and molds. At the polish stage, farmers may also add colorants to the turmeric to make it appear more attractive to buyers in order to assure a sale.

While we can see a picture of price volatility in the local turmeric market, fortunately for most farmers, turmeric is grown alongside other crops. Sugar cane is often the primary crop grown in the Erode area due to the presence of several large sugar manufacturers who are able to provide some market stability. Other crops grown in the area are tapioca, coconut, rice, bananas, papaya, maize and okra. The dominant crops tend to reflect market prices so if the price is good one year, more of that crop is planted for the next year. However, farmers told us that this pattern of response often has the effect of over-supplying the market in subsequent years, resulting in a decrease in value. 
The third site was farm in Jhansi, northern India that sold turmeric only to local market traders and had no connection with, and little understanding of, the industrial chain. At this site in-depth interviews were conducted at a farm, less than 0.5 hectare in size, that produced peanuts (Arachis hypogaea) and turmeric. The farmer and his family cultivated turmeric to sell in the local market. It is not boiled, polished or even dried but sold directly to market traders after harvesting. The farmers sell the crop to middlemen for 25 rupees per $\mathrm{kg}$, which is less than either of the other case studies. Turmeric is always grown as a 'standby' crop, in case of a sudden rise in its market value, as was seen in previous years. Using this strategy, the farmers have some turmeric ready to sell and have enough seed stock in the form of the root tubers for replanting when necessary.

Standards and Governance of GVC for turmeric in India

The two broad types of chain result are associated with different end product qualities. I $n$ the captive chain (Figure 1) there is no requirement for a polishing step and the rhizomes are collected for extraction immediately after drying. Moreover, the agreed contract price negates any need for storage and so heat sensitive compounds are more likely to remain intact and treatment with aggressive pesticides and preservatives is unnecessary. Moreover, the adherence to private standards of organic production requires that in the captive chain, methods of production do not involve the application of non-organic inputs, such as synthetic pesticides and fertilizers. By establishing a well-managed and well monitored captive value chain, end companies can exert a greater degree of control over processes and procedures that can lead to a better quality product. The chemical analysis provided crucial evidence to support this by demonstrating that the samples obtained from the captive value chain were free from adulterants and were comparably closer in chemical 
composition to the freshest rhizomes tested than most other samples in the study (Booker et al., 2014).

This study has shown that, in the market-based value chain, methods of cultivating, storing and selling Curcuma longa can lead to adulteration of the supply chain. As well as the mixing of incorrect curcuma species, this adulteration often takes place at the polishing stage, where ground powders are added to improve the color of the rhizomes. As the captive value chain product is not polished and is not destined to be sold at auction, (in the auction good color is likely to have an incremental effect on the price), product adulteration is more effectively controlled and prevented. Adulteration can also happen in the market-based value chain during storage, when synthetic preservatives are deliberately applied or when poor storage facilities lead to accidental contamination. More than that, the analysis of some of the samples of medicinal turmeric purchased in the UK suggested the starting material had been stored for long periods, resulting in deficiency of what may be important therapeutic compounds.

Having considered the different factors determining product quality, let us turn to the governance of each chain. In Shimoga (Case study 1 ), the risks for the farmers have been minimized through the establishment of contracts that guarantee an order size and a price for the crop. The farmers in the captive chain are directed through the buyer as to which plant to grow, how to cultivate and what quantity. Farmers receive training in organic production and in good agricultural practices (GAP). We have already noted that farmers received more than twice the price for their turmeric than those in Erode at the time of fieldwork (although the auction price can also peak at a higher level). Interestingly, another benefit of the stability of the market for turmeric was that, our interviews with both farmers and workers suggested that while the farmworkers in the case study 1 earned the same daily wage as in case study 2 , they had longer employment periods and far more secure forms of 
employment contract. As such interviews suggested that they were paid about US $\$ 0.12$ for work that produced about a kilo of turmeric in both sites. However, in the Shimoga farm supplying the captive value chain, most workers seemed to have formal contracts and the availability of work appeared to be more consistent through the year. In Jhansi (site three), the farmers engaged on very small farms appeared to be the less affluent of all the farmers studied. These farmers had no means to engage with any outside markets and relied on selling their unprocessed turmeric for the minimal price at local markets. Farm workers on these very small plots worked for food (i.e. where they are paid in kind wages) and were accommodated in the homestead. As such it was hard to calculate an equivalent daily wage, but they seemed to have the poorest working conditions in the sample.

In the Erode site (Case study 2), interviews suggested that farmers were aware of turmeric's use in medicinal products and chose to sell their crop at the state-run auction house. This gave them the possibility of selling when the price was high and also they could take advantage of the storage facilities provided in the town of Erode when the market price was low. They expressed interest in selling directly to herbal medicine manufacturers and especially those outside of India but did not have the necessary linkages in place. They accepted that there was a market for organically produced, export-quality turmeric but lacked expertise in this area and were not prepared to undertake any changes that, in their view, could easily result in a loss of income. Paradoxically, they were unhappy with the low market value of the domestic market and their necessary but uncomfortable reliance on middlemen.

In case study 1 , the captive value chain, the quality and traceability of the raw materials used to manufacture phytomedicines are crucial to the domestic primary processor as they must adhere both to public health standards and the private, organic standard. For the domestic market in India, private standards are less common and companies producing medicinal turmeric products often obtain their supplies through middlemen or through the state-run 
auction houses. Some Indian herbal manufacturing companies have started to produce organic products. In this study, the primary processing company (PP) in Bangalore is contracted to supply the European manufacturer (the lead firm). In order to achieve this, PP make contracts with farmers in order to fulfil the order requirements of the lead firm, and in this case, PP has become the major supplier of the lead firm. At the same time, PP is reliant on sales to the lead firm, with the majority of medicinal plants processed destined for secondary manufacture by the lead firm. PP plans contracts with farmers in advance, based on market predictions from the lead firm.

However, the lead firm does not only deal in India but have contracts with over one hundred farmers in many parts of the world, including Sri Lanka, China, Vietnam and Eastern Europe. Through making these contracts and paying a premium for organically produced crops, the lead firm is able to assert the organic nature of their products, as well as claim full traceability. Moreover, in interviews it was clear that the stability of the relationships that they enter into allows them to present their relationships under a 'fair trade' ethic, which is useful as a marketing tool. This represents a considerable investment for the lead firm in terms of time and money, as in practice this means that the lead firm must send employees to visit the farms on a regular basis to ensure that standards are met. Training is provided to the farmers, farm workers and the workers at the primary processing facilities to ensure compliance with the manufacturer's product specification

Discussion and implications

The case study above serves to illuminate some of the debates about the impact of standards in agricultural trade. We have seen that the most recent literature has tended to distinguish the impact of public and private standards on varying groups of farmers. What 
does this qualitative, contrastive study of turmeric tell us about the impact of standards and international trade? Turmeric must be understood as product sold on complex and interacting value chains. This of course is true of most agricultural products (Tran et al 2013), and each value chain has different governance standards. Both public and private standards restrict entry to the most profitable market for farmers - the organic medicinal chain. Interestingly, primary processors are likely to find that the profitability of the domestic organic medicinal turmeric market is greater than the export market (due to differences in testing costs but similar prices received). In the domestic Indian medicinal market, the public standards are not as stringent, and indeed many local health practices advocate the ingestion of heavy metals (Kumar et al., 2006).

Volatility and competition in the domestic market leads farmers to adopt a range of practices that can lead to contamination of the crop. Farmers may add colorant in order to make their crop visually attractive to traders or add in other species to bulk out the crop. Or, like the rosy periwinkle farmers in Neimark (2012:442)'s study, some wealthier farmers might put their plants in storage, in order to ride out dips in the market price. This leads to risks of further contamination from pesticide and mold. This research suggests that Tran et al's (2013) conclusions about the ability of small famers to meet public food safety standards in shrimp may not apply in other crops. While some of the crop contamination might disappear with a less volatile domestic turmeric market, other kinds of contamination are the result of competition in unintegrated markets and would be likely to continue.

The study of turmeric also suggests a far more complex class division of farmers than is often recognized in value chain studies. The simple division of farmers into 'small vs. large' is an abstraction that ignores a range of differences in the degree of capitalization, 
specialization and dependence on the market (Oya 2004). These differences affect the way that farmers are able to access value chains. While this study lacks a wider picture of capitalization and size distribution of farmers, it appeared from the stakeholder interviews that it was the largest and wealthiest farmers who were able to benefit from integration in the most profitable value chain with the most stringent standards. This confirms the conclusions of the existing literature. However, the qualitative information collected in this study suggests that integration in the organic export market was not just about size of holding, but, given the existence of larger farmers who were trying to switch out of agriculture, reflected the degree of dependence on the agricultural market, ability to invest and, fundamentally, links to an appropriate processor. This raises the need for more studies that go beyond the small-large dichotomy to understand agricultural success.

In conclusion, the captive (or vertically integrated) chain can encourage high quality and increases in the productivity of cultivated turmeric. In this sense, it provides support for those writers who consider vertical integration of herbal value chains a solution to the increasing pressure on environmental resources and the low profitability and quality of many Indian herbal products. As Coslovsky (2014:33) argues, this is a case where integration with the lead firm improves performance on various fronts. We saw that the lead firm worked with the primary processor and with farmers to improve production techniques generally, as well as in the specific area of organic production. This contrasts with other case studies of medicinal value chain production. Neimark's (2012:426) discussion of rosy periwinkle production in Madagascar suggests that pharmaceutical firms shift tasks of harvesting, transporting and quality control to small scale collectors in order to overcome the risks of contending with natural cycles and marshalling of labor. In our study of medicinal turmeric production in India, it may be that the particular combination of public and private standards forces a very different kind of response by pharmaceutical manufacturers, who are then unable to delegate quality control. 
For the farmer, the benefits to producing in this chain are clear. Prices are stable, and are relatively high. Moreover, farmers receive training on improved production techniques and benefit from access to inputs. However, although a captive value chain may appear to be more stable and less of a risk to the farmer there are some instances where the farmer may not benefit. Once contracted into a chain, our interviewees told us that a certain amount of freedom is given up and the farmer is no longer free to sell on the open market. Finally, it appears that only the largest and most capitalized farm in the study was able to engage in this chain, although greater evidence would be needed on the distribution of farm size and capitalization to make a firm conclusion.

The quality benefits for consumers of the captive value chain are clear. They are able to consume a product that is high in key ingredients and low in adulterants. Tran et al (2013: 334) have called this a 'moral beauty contest', where on the one hand the rights to consume safe and certified products in the industrial North have been expanded, while on the other hand the rights of small-scale producers to earn a livelihood in the developing South have contracted. This study complicates Tran et al's analysis, by suggesting that there may be safety hazards for domestic consumers of turmeric, for either food or medicinal use. These hazards are not the result of the development of an organic export value chain, but arise because of the competition and volatility of the unregulated domestic market. This suggests that the 'morality' of production is quite complex, and that domestic Indian consumers of turmeric would benefit from the introduction of health standards.

\section{CONCLUSION}

A growing export market and the activities of international pharmaceutical companies in medicinal plant production in India have changed the way that some farmers and processors work. This pattern has to be understood in the light of shifts in standard setting in affluent markets. While some standards are public health regulations, others are privately adopted and intended to capture consumer aspirations around product quality. However, public and 
private standards may have reduced the room for pharmaceutical processors to rely on small-scale collectors and farmers. Indeed, in this case study, international pharmaceutical companies are seeking out long-term relationships with primary processors, who themselves are entering into long term contracts with larger and more dynamic farmers. In contrast, smaller or non-specialist producers sell onto a volatile 'free' domestic market, which encourages low quality due to competition and storage. Thus, this is a complex set of interrelated value chains, where developments in end markets can fundamentally affect the structure and benefits of production.

This particular example suggests that there are a complex set of risks and opportunities for different kinds of farmer. For those dynamic farmers, there is a benefit in terms of relatively high price, lack of price volatility, and access to training and inputs. There are also benefits for consumers. Interestingly, the increased capacity of primary processors to manufacture a high quality, organic product has encouraged some to begin to sell to the domestic market, and so both affluent Indian and European consumers benefit from a product high in active ingredients and free from adulterants.

It is understandable that researchers are worried about the exclusionary nature of standard setting. This research confirms the results of others studies by suggesting that only certain farmers can produce organic medicinal turmeric. However, the answer is not to simply reduce the content of standards, as, in this case, the unregulated market encourages production that may be contaminated by mold, heavy metals and pesticides. Indeed, this research contradicts other studies that suggest that small farmers are not excluded by public health standards in northern countries. This discussion is also relevant to the debate over the development potential of plant-based medicinal, reviewed above, and may support those authors, such as Kala et al. (2006) who argue that public intervention is necessary to assist small farmers to benefit from the creation of new value chains. 
The strengths of this research are in being able to link a chemical analysis of quality with various value chains. This is the advantage of a multidisciplinary approach that married qualitative research with pharmacognosy. The weaknesses are that it cannot make claims to generalizability and further, quantitative investigation may be needed to pin down more clearly the pattern of costs and benefits in this value chain. However, the results are certainly challenging and suggest that we should not discount the benefits of either integration or standard setting, while recognizing how they are likely to increase farmer differentiation.

\footnotetext{
'The role of consumer perceptions is also relevant for non-medicinal agricultural trade. Coslovsky (2014:32) notes the impact of both real and imagined health scares, while other agricultural products may suddenly move into or out of fashion, such as quinoa or shea butter.

ii Our contrastive case study approach is similar in style to the work of authors, such as DuPuis et al (2005), who have investigated alternative food supply systems. DuPuis et al note how the choice of analytical approach can edit out important questions and can direct attention to particular features. Thus the discussion of the emergence of new 'local' food supply chains has tended to focus attention on the internal dynamics of this shift, and neglects the wider questions of the politics and power in the supply chain as a whole.

iii Ayurvedic medicine is the most common system of traditional medicine found in India and stems from ancient texts of the Hindu religion.

${ }^{\text {iv }}$ The polishing method is used throughout India, either manually or using semi-automated machinery
} 


\section{REFERENCES}

Alam, G., Belt, J. 2009. Developing a medicinal plant value chain: Lessons from an initiative to cultivate Kutki (Picrorhiza kurrooa) in Northern India, KIT Working Papers Series C5. KIT, Amsterdam.

Bair, Jennifer. 2005. Global Capitalism and Commodity Chains: Looking Back, Going Forward. Competition \& Change, 9, (2) 153-180.

Barrett, C. B., Bachke, M. E., Bellemare, M. F., Michelson, H. C., Narayanan, S., \& Walker, T. F. (2012). Smallholder participation in contract farming: comparative evidence from five countries. World Development, 40, (4) 715-730.

Bellemare, Marc F. 2012. As you sow, so shall you reap: The welfare impacts of contract farming. World Development 40, (7) 1418-1434.

Bernstein H. \& L. Campling. 2006. Commodity Studies and Commodity Fetishism II: Profits with Principles? Journal of Agrarian Change, 6, (3) 414-447.

Booker, A., Frommenwiler, D., Johnston, D., Umealajekwu, C., Reich, E., Heinrich, M. 2014. Chemical variability along the value chains of turmeric (Curcuma longa): A comparison of Nuclear Magnetic Resonance Spectroscopy and High Performance Thin Layer Chromatography. Journal of Ethnopharmacology doi: 10.1016/j.jep.2013.12.042.

Booker, A. J. 2014. The Transformation of Traditional Asian Medical Knowledge into International Commodities - the Link between Traditional Medicines and the International Market.) PhD thesis. Centre for Pharmacognosy and Phytotherapy, School of Pharmacy. London, UCL.

Cavaliere, C. 2010. Efforts to Increase Sustainability of Ayurvedic Plants in India. Herbalgram, 22-23.

Coslovsky, S. V. 2014. Economic Development without Pre-Requisites: How Bolivian Producers Met Strict Food Safety Standards and Dominated the Global Brazil-Nut Market. World Development, 54, 32-45. 
Dharmananda, S. 2003. The Ayurvedic medicine industry in India, Institute for Traditional Medicine, Portland, Oregon. Published online. Available at http://www.itmonline.org/arts/ayurind.htm

DuPuis, E. M., Goodman, D., \& Harrison, J. (2005). Just values or just value? Remaking the local in agro-food studies. Research in Rural Sociology and Development, 12, 241.

Euromonitor, 2013. Herbal / Traditional Products in India, Consumer Health. Published online. Available at http://www.euromonitor.com/herbal-traditional-products-in-india/report

FAO, 1990. The community's toolbox: The idea, methods and tools for participatory assessment, monitoring and evaluation in community forestry, Community Forestry Field Manuals. Food and Agriculture Organization of The United Nations., Rome, Italy.

Fullbright, 2008. Product chain study, orthodox tea. Commercial agriculture development project.

Gibbon, P., Ponte, S., 2005. Trading Down: Africa, value chains and the global economy. Temple University Press, Philadelphia, USA.

Handley, K., 2012. Non-participant observation, The SAGE dictionary of qualitative research. Hansen, H., Trifković, N. 2014. Food Standards are Good-for Middle-Class Farmers. World Development, 56, 226-242.

Heinrich, M., Danji, T., Casselman, I. 2011. Acai (Euterpe oleracea Mart.)- a phytochemical and pharmacological assessment of the species' health claims. Phytochemistry Letters 4, 10-21.

Jurenka, J.S. 2009. Anti-inflammatory properties of curcumin, a major constituent of Curcuma longa: A review of preclinical and clinical research. Alternative Medicine Review 14, 141-153.

Kala, C., Dhyani, P., Sajwan, B. 2006. Developing the medicinal plants sector in northern India: challenges and opportunities. Journal of Ethnobiology and Ethnomedicine 2, 32.

Kaplinsky, R., 2004. Competitions policy and the global coffee and cocoa value chain. United Nations, Paper prepared for the United Nations Conference for Trade and Development (UNCTAD). 
Kaplinsky, R., Morris, M., 2001. A Handbook of Value Chain Research. IDRC.

Kumar, A., Nair, A.G., Reddy, A.V., Garg, A.N., 2006. Bhasmas: unique ayurvedic metallicherbal preparations, chemical characterization. Biological Trace Elements Research 109, 231-254.

LaRosa, J., 2011. U.S. Weight Loss Market Worth $\$ 60.9$ Billion. PRWebb, Florida. Published online. Available at http://www.prweb.com/releases/2011/5/prweb8393658.htm

Masakure, Oliver, and Spencer Henson. 2005. Why do small-scale producers choose to produce under contract? Lessons from nontraditional vegetable exports from Zimbabwe. World Development 33, (10) 1721-1733.

Melo, O., Engler, A., Nahuehual, L., Cofre, G., \& Barrena, J. 2014. Do Sanitary, Phytosanitary, and Quality-related Standards Affect International Trade? Evidence from Chilean Fruit Exports. World Development, 54, 350-359.

NCDEX 2015. Commodity Futures. Turmeric. Published online. Available at http://www.ncdex.com/MarketData/FuturePrices.aspx

Neimark, B., 2012. Green grabbing at the 'pharm' gate: rosy periwinkle production in southern Madagascar. Journal of Pesant Studies 39, 423-445.

Ortiz, Sutti. Aparicio, Susana. 2007. How labourers fare in fresh fruit export industries: Lemon production in Northern Argentina. Journal of Agrarian Change, 7, (3) 382-404.

Oya C. 2004. The empirical investigation of rural class formation: methodological issues in a study of large- and mid-scale farmers in Sengal. Historical Materialism, 12, 289-326.

Palpacuer, Florence. 2008. Bringing the social context back in: governance and wealth distribution in global commodity chains. Economy and Society 37, (3) 393-419.

Patwardhan, B. 2011. European Union ban on Ayurvedic Medicines. Ayurveda Integrated Medicine. 2, 47-48.

Patwardhan, B., Warude, D., Pushpangadan, P., Bhatt, N. 2005. Ayurveda and traditional Chinese medicine: a comparative overview. Evidence Based Complementary and Alternative Medicine, 2, 465-473. 
Polshettiwar, S. 2006. Indian herbal drug industry - Future prospects: A review Ayurveda emphasis relationship between man and plants throughout the development of human culture., Reviews. Pharmainfo.net.

Prasad, S., Aggarwal, B.B. 2011. Turmeric, the Golden Spice: From Traditional Medicine to Modern Medicine, in: Benzie, I.F.F., Wachtel-Galor, S. (Eds.), Herbal Medicine: Biomolecular and Clinical Aspects. CRC Press Llc., Boca Raton (FL).

Ravishankar, B., Shukla, V.J. 2007. Indian Systems of Medicine: A Brief Profile. African Journal of Traditional, Complementary and Alternative Medicine 4, 319-337.

Riisgaard, L. 2009. Global Value Chains, Labor Organization and Private Social Standards: Lessons from East African Cut Flower Industries. World Development, 37 (2) 326-340.

Robinson, M.M., Zhang, X. 2012. The World Medicines Situation 2011, 3rd ed. WHO, Geneva.

Romanowski, P. 2010. A Cosmetic Industry Overview for Cosmetic Chemists. Published on the internet. Available at http://chemistscorner.com/a-cosmetic-market-overview-forcosmetic-chemists/

Schippmann, U., Leaman, D., Cunningham, A. 2002. Impact of cultivation and Gathering of Medicinal Plants on Biodiversity: Global Trends and Issues, Biodiversity and the Ecosystem Approach in Agriculture. Food and Agriculture Organization of the United Nations, Rome, Italy, 1-21.

Scindia, J.M. 2010. India's herbal product exports rising at a compounded annual rate of 16.8 per cent news, Industry. Domain-B.com, Published on the internet.

Selwyn, B. 2007. Labour process and workers' bargaining power in export grape production, North East Brazil. Journal of Agrarian Change, 7 (4) 526-33.

Shahidullah, A.K.M., Haque, C.E. 2010. Linking Medicinal Plant Production with Livelihood Enhancement in Bangladesh: Implications of a Vertically Integrated Value Chain. The Journal of Transdisciplinary Environmental Studies 9, 1-18.

Sharma, A., Shanker, C., Tyagi, L.K., Singh, M., Rao, V. 2008. Herbal Medicine for Market Potential in India: An Overview. Academic Journal of Plant Sciences 1, 26-36. 
Smith, A., Rainnie, A., Dunford, M., Hardy, J., Hudson, R., \& Sadler, D. 2002. Networks of Value, Commodities and Regions: Reworking Divisions of Labour in Macro-Regional Economies. Progress in Human Geography, 26 (1) 41-63.

Spices Board. 2015. Spices Board (Ministry of Commerce \& Industry, Govt. of India) N.H.By Pass, Palarivattom.P.OCochin - 682025, Kerala, India. Published online. Available at http://www.indianspices.com/html/s0420sts.htm

Subrat, N., lyer, M., Prasad, R. 2002. The ayurvedic medicine industry: Current status and sustainability. Ecotech Services (India) Pvt. Ltd. and International Institute for Environment and Development.

Thorne, 2002. Curcuma longa. Thorne Research Inc., Alternative Medicine Review Monographs.

Tran, N., Bailey, C., Wilson, N., \& Phillips, M. 2013. Governance of Global Value Chains in Response to Food Safety and Certification Standards: The Case of Shrimp from Vietnam. World Development, 45, 325-336.

USDA, 2009. India- Agricultural economy and policy report.

Vaidya, A.D.B., Devasagayam, T.P.A. 2007. Current Status of Herbal Drugs in India: An Overview, Journal of Clinical Biochemistry and Nutrition, 1-11.

van de Kop, P., Alam, G., de Steenhuijsen Piters, B., 2006. Developing a sustainable medicinal plant chain in India. Linking people, markets and values, in: Ruben, R., Slingerland, M., Nijhoff, H. (Eds.), Agro food chains and networks for development. Springer, Netherlands, 191-237.

Velayudhan, K.C., Dikshit, N., Nizar, M.A. 2012. Ethnobotany of Turmeric (Curcuma longa L.). Indian Journal of Traditional Knowledge 11, 607-614.

Watts, M.J. 1994. Life under contract: contract farming, agrarian restructuring, and flexible accumulation. In: P.D. Little and M.J. Watts, eds. Living under contract: contract farming and agrarian transformation in sub-Saharan Africa. Madison, WI: University of Wisconsin Press, 21-77. 
Yeoh, W. 2010. Prices of herbs shoot up, Archives. The Star Online. Published online. Available

http://www.thestar.com.my/story/?sec=nation\&file=\%2f2010\%2f4\%2f9\%2fnation\%2f2010040

9130135

Table 1: List of Interviewees in each value chain

\begin{tabular}{|l|l|l|}
\hline Interviewee & Location & Case study / chain \\
\hline Operations manager & Lead firm, UK & Shimoga (Case 1) \\
\hline Herbal products Director & Lead firm, UK & Shimoga (Case 1) \\
\hline Biolab Manager & Primary processor (PP), India & Shimoga (Case 1) \\
\hline Managing Director & Primary processor (PP), India & Shimoga (Case 1) \\
\hline Accounts Manager & Primary processor (PP), India & Shimoga (Case 1) \\
\hline Retail Manager & Primary processor (PP), India & Shimoga (Case 1) \\
\hline Production manager & Primary processor (PP), India & Shimoga (Case 1) \\
\hline Farm Manager & Karnataka, India & Shimoga (Case 1) \\
\hline Company Director & Processing company, Erode & Erode (Case 2) \\
\hline $\begin{array}{l}\text { Director of Medicinal plant } \\
\text { farm }\end{array}$ & Medicinal plant farm & Erode(Case 2) \\
\hline Forestry representative & Indian Forest Service (IFS) & Erode (Case 2) \\
\hline Farm owner 1 & Tamil Nadu Farm, Tamil Nadu, & Erode (Case 2) \\
\hline Farm owner 2 & India & Jhansi, India \\
\hline Farm owner 2 & Jamil Nadu Farm, Tamil Nadu, India & Erode (Case 2) \\
\hline
\end{tabular}




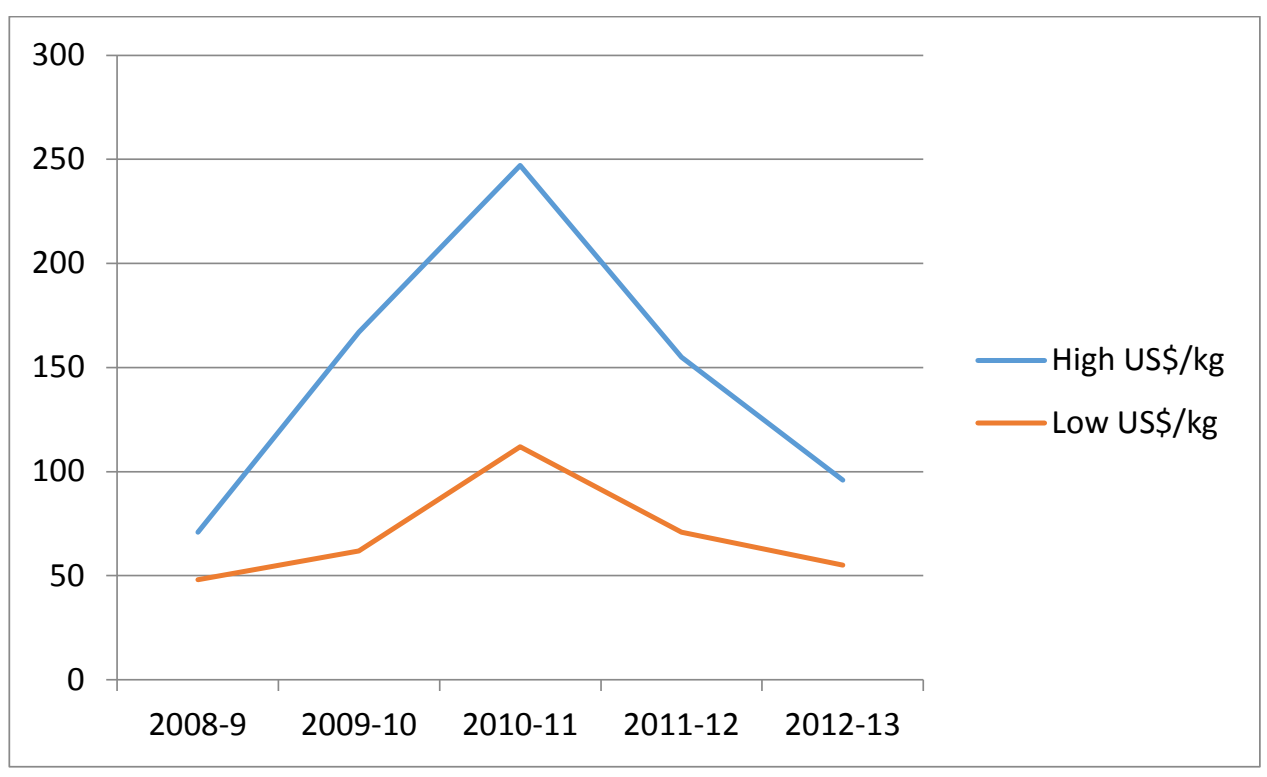

Figure 2. Chart showing the Erode auction price highs and lows for turmeric from 2008 to 2013.

Source: NCDEX (2015) 
